\title{
EFEITOS DO SISTEMA DE CONDUÇÃO, PODA E IRRIGAÇÃO NA PRODUÇÃO DO MARACUJAZEIRO DOCE ${ }^{1}$
}

\author{
HELENA ADÉLIA DA SILVA², LUIZ DE SOUZA CORRÊA, APARECIDA CONCEIÇÃO BOLIANI ${ }^{4}$
}

\begin{abstract}
RESUMO - O maracujá é um fruto de ampla aceitação dada a qualidade de seu suco, sendo o maracujazeiro-amarelo o mais cultivado no Brasil. Nos últimos anos, cresceu o interesse pelo maracujazeiro doce, em função de alcançar bons preços no mercado in natura. Assim, informações técnicas por parte dos agricultores têm se intensificado. Este trabalho teve como objetivo avaliar a produção e a qualidade dos frutos desta espécie, cultivada sob poda e irrigação em diferentes sistemas de condução. O experimento foi conduzido no delineamento em faixas, contendo 12 tratamentos (plantas com e sem irrigação, com e sem poda e três sistemas de condução) e 3 repetições. Com base nos resultados obtidos, pode-se concluir: a) o sistema de condução e a poda não afetaram o tamanho dos frutos; b) o sistema de condução não afetou a massa dos frutos, porém as plantas podadas produziram frutos com maior massa; c) a poda diminuiu o número de frutos por planta e o rendimento por área, nos sistemas de condução em T normal e espaldeira vertical com um fio de arame; d) a poda não alterou o número de frutos por planta e o rendimento por área, no sistema de condução em espaldeira vertical com dois fios de arame.
\end{abstract}

Termos para indexação: maracujá, tratos culturais, espaldeira, Passiflora alata, frutos.

\section{EFFECT OF MANAGEMENT SYSTEM, PRUNING AND IRRIGATION ON FRUITS PRODUCTION OF SWEET PASSION FRUIT}

\begin{abstract}
The passion fruit is a fruit of large acceptance due to its juice quality, being the yellow passion fruit plant more cultivated in Brazil. In the last years, the interest for the sweet passion fruit plant increased because the good price in the market 'in natura'. This work had as objective to evaluate production and fruit quality of this species, cultivated with pruning and irrigation in different management systems. The experiment was carried out at randomized block design in strip with 12 treatments ( 3 management systems x plant irrigated or not x plant pruned or not) in 3 replications. It can be concluded: a) the management systems and the pruning did not affect the fruit size; $b$ ) the management systems did not affect the fruit mass; however, the pruned plants produced fruits with bigger mass; c) the pruning reduced the number of fruits per plant and the fruit yield, in the management systems normal "T" and vertical cordon with two wire threads; d) the pruning did not affect the number of fruits per plant and the fruit yield, in the management system in vertical cordon with two wire threads.
\end{abstract}

Index terms: passion fruit, crop management, vertical cordon, Passiflora alata, fruits.

\section{INTRODUÇÃO}

O maracujazeiro pertence à família Passifloraceae, gênero Passiflora, com cerca de 430 espécies descritas, sendo que, no Brasil, o maior centro de distribuição geográfica destas espécies localiza-se no Centro-Norte do País (Oliveira, 1996).

O maracujazeiro amarelo (Passiflora edulis Sims. f. flavicarpa Deg.) é a espécie mais cultivado no Brasil. Por outro lado, tem crescido o interesse pelo maracujazeiro doce (Passiflora alata Curtis) devido à qualidade dos frutos para consumo in natura e preços alcançados no mercado, além de ser resistente a fusarium. Os frutos apresentam diâmetro médio ao redor de $8,16 \mathrm{~cm}$, comprimento de $9,59 \mathrm{~cm}$ e massa média de 256,13 g (Vasconcellos et al., 1993). Martins et al. (2003) obtiveram, com cinco populações da mesma espécie em Jaboticabal-SP, plantas que produziram de 1,43 a $69,87 \mathrm{~kg}$ de frutos e frutos com massa média entre 136,88 e $368,19 \mathrm{~g}$.

Por ser uma planta trepadeira, precisa de um sistema de sustentação para sua condução, sendo tradicionalmente utilizados quatro: latada ou caramanchão, espaldeira em T, espaldeira em cruz e espaldeira vertical com um ou dois fios de arame. O mais utilizado e econômico para a condução do maracujazeiro-amarelo é a espaldeira com um fio de arame (Albuquerque \& Albuquerque, 1988). No maracujazeiro doce, tem sido utilizada a latada e a espaldeira vertical.

O maracujazeiro é uma planta que floresce e frutifica vários meses por ano, sendo influenciado pelo fotoperíodo, temperatura e disponibilidade de água. Assim, a distribuição das chuvas ou irrigação assume grande importância para uma boa produção. Porém, o efeito da irrigação é pouco estudado para a cultura, em que pese que esta pode alongar o período de produção, aumentando a produtividade, além de melhorar a qualidade do fruto (Manica, 1981 e Ruggiero, 1987). Lucas (2002) verificou com maracujazeiro-amarelo em Piracicaba-SP, que suplementação de $118,5 \mathrm{~mm}$ para uma precipitação, em 13 meses, de $1.345,6 \mathrm{~mm}$, proporcionou aumento na produção.

A produção de frutos ocorre em ramos do ano, o que propicia acúmulo de massa vegetal no sistema de condução com o passar dos anos, evidenciando a necessidade de uso da poda. Nestes destacam-se: a poda de limpeza, que consiste na eliminação dos ramos secos e doentes, e a poda de renovação, que consiste no corte de ramos secundários e terciários, após a frutificação dos mesmos, até três a quatro nós (gemas) em relação à base (Teixeira, 1994).

Buell (1955) avaliou a poda sobre a frutificação do maracujazeiroroxo (Passiflora edulis Sims.), constatando que a poda no $2^{\circ}$ nó dos ramos secundários propiciou maior número de frutos. Acrescenta ainda que a época deve ser ajustada ao florescimento das plantas, evitando os meses secos ou chuvosos, pois a brotação será fraca no primeiro caso e excessiva no segundo

A poda na frutificação no maracujazeiro-amarelo é benéfica, pois as produções do segundo e terceiro anos mantiveram-se sem grandes variações, e quando feita a $75 \mathrm{~cm}$ do tronco (corte transversal ao arame), propiciou a melhor produtividade (Cereda, 1976). Segundo Cereda \& Urashima (1989), a poda no maracujazeiro-amarelo deve ser realizada, no Estado de São Paulo, no mês de agosto. Em relação ao maracujazeiro doce, não foram encontrados dados a respeito.

Pelo exposto, constata-se que existem poucas informações sobre condução, poda e irrigação com a cultura, e em especial com o maracujazeiro doce, pesquisas sobre os assuntos mencionados não existem.

Este trabalho teve como objetivo avaliar a produção e a

\footnotetext{
$\overline{1}$ (Trabalho 082/2004). Recebido: 30/06/2004. Aceito para publicação:28/10/2004

${ }^{2} \mathrm{Eng}^{\circ} \mathrm{Agr}^{\circ}$, M. Sc, Bolsista FAPESP, CATI, Passeio Laguna, 422, 15385-000, Ilha Solteira-SP, Brasil.

${ }^{3}$ ProfessorTitular da Universidade Estadual Paulista, Depto. Fitotecnia, Tecnologia de Alimentos e Sócio-Economia da UNESP, Av. Brasil, 56, C.P. 15385-000, Ilha Solteira-SP, (18) 3743 1248. lcorrea@feis.unesp.br.

${ }^{4}$ Professor Adjunto da Universidade Estadual Paulista, Depto. Fitotecnia, Tecnologia de Alimentos e Sócio-Economia da UNESP, Av. Brasil, 56, C.P. 15385-000, Ilha Solteira-SP, (18) 3743 1243. boliani@agr.feis.unesp.br.
}

Rev. Bras. Frutic., Jaboticabal - SP, v. 26, n. 3, p. 450-453, Dezembro 2004 
qualidade dos frutos do maracujazeiro doce, cultivados com poda e irrigação sob diversos sistemas de condução.

\section{MATERIAL E MÉTODOS}

O experimento foi conduzido no município de Selvíria-MS, localizado entre as seguintes coordenadas geográficas: $20^{\circ} 22^{\prime}$ Latitude Sul , 51 ${ }^{\circ} 22^{\prime}$ Longitude Oeste de Greenwich, e com aproximadamente 335 metros de altitude . O clima da região é Aw, segundo a classificação de Köeppen, apresentando uma temperatura média anual de $25{ }^{\circ} \mathrm{C}$ e uma precipitação total anual de $1.330 \mathrm{~mm}$ (Centurion, 1982). O solo da área do experimento é um LATOSSOLO VERMELHO (Demattê, 1980 e Embrapa, 1999).

A espécie utilizada foi a Passiflora alata Curtis, conhecida como maracujá-doce. As mudas obtidas de sementes foram plantadas no dia 27-05-96 em covas preparadas com $1 \mathrm{~kg}$ de Minercal, $190 \mathrm{~g}$ de $\mathrm{P}_{2} \mathrm{O}_{5}$ e $60 \mathrm{~g}$ de $\mathrm{K}_{2} \mathrm{O}$. Foram feitas bacias com 1,2 $\mathrm{m}$ de diâmetro em cada cova, para irrigação das plantas.

Utilizou-se a condução em espaldeira vertical com um e com dois fios de arame e espaldeira em "T", no espaçamento de $2 \mathrm{~m}$ entre plantas e $3 \mathrm{~m}$ entre linhas. A irrigação foi localizada, tendo sido colocado 70 litros de água na bacia de cada planta, semanalmente, sempre que necessário (precipitação inferior a $20 \mathrm{~mm}$ ). Dentro de cada bloco, a bordadura entre plantas irrigadas e não-irrigadas foi de três plantas. A precipitação total no período de maio a dezembro de 1996 foi de $806,4 \mathrm{~mm}$ (maio- 134,4; jun- 15,8; jul- 1,0; ago- 13,2; set-87,6; out- 156,1; nov-174,9 e dez-223,4mm); no ano de 1997 foi de $1.669,5 \mathrm{~mm}$ (jan-313,6; fev- 139,6; mar- 196,2; abr- 39,3; maio- 72,0; jun- 238,0; jul- 2,8; ago- 0,0; set- 25,3; out- 89,1 ; nov- 217,1 e dez- $197,4 \mathrm{~mm}$ ) e de janeiro a agosto de 1998 foi de $773,8 \mathrm{~mm}$ (jan- 195,8 ; fev- 154,0; mar- 175,6; abr- 132,6; maio- 101,5; jun$0,0$; jul- 4,7 e ago- $9,6 \mathrm{~mm})$.

As plantas foram conduzidas em haste única até atingirem o arame superior da espaldeira, a uma altura de dois metros. Ao atingirem esse ponto, foram despontadas, realizando-se a condução dos cordões laterais, e destes os verticais, formando a condução em cortina.

No dia 14-08-97, realizou-se a poda de renovação, utilizando-se a recomendação de época de poda para o maracujazeiro azedo, tendo sido obtida a produção até maio de 1998 . Esta poda consistiu na eliminação dos ramos terciários no $2^{20}$ nó, a partir dos cordões laterais.

Foram realizados os tratos culturais normalmente utilizados na cultura do maracujazeiro para o Estado de São Paulo, cabendo salientar a polinização manual, adubações feitas de acordo com a análise do solo, bem como tratamento fitossanitário, visando ao controle de pragas e doenças.

Foi utilizado o delineamento experimental em faixas, contendo 12 tratamentos (plantas com e sem irrigação, com e sem poda e três sistemas de condução), constituído por 3 repetições e 4 plantas úteis por parcelas. Foram avaliados os seguintes parâmetros: tamanho dos frutos (diâmetro e comprimento) com auxílio de um paquímetro, número de frutos por planta, massa média dos frutos ( balança com sensibilidade de $0,01 \mathrm{~g}$ ) e rendimento por área.

\section{RESULTADOS E DISCUSSÃO}

\section{Diâmetro dos frutos}

Pelos valores de diâmetro médio dos frutos colhidos durante as safras de 1997 e 1998 (Tabela 1), verifica-se que não houve diferença estatística significativa nos tratamentos isolados, bem como nas interações entre os tratamentos. Desta forma, o diâmetro do fruto não foi alterado pelo sistema de condução, poda e irrigação. A falta de efeito da irrigação provavelmente seja devida à alta e bem distribuída precipitação no período. O diâmetro médio dos frutos colhidos não diferiu muito dos obtidos por Vasconcellos et al. (1993), que foi de $8,16 \mathrm{~cm}$.

\section{Comprimento dos frutos}

Os valores de comprimento médio dos frutos não diferiram significativamente nos tratamentos isolados, bem como nas interações entre os tratamentos (Tabela 1). Assim, o comprimento do fruto não foi alterado pelo sistema de condução, poda e irrigação.

A falta de efeito da irrigação provavelmente seja devida à alta precipitação ocorrida ao longo do período de condução do experimento. O comprimento médio dos frutos ao longo das safras de 1997 e 1998 variaram entre 10,10 e $11,55 \mathrm{~cm}$, sendo que esses resultados foram semelhantes aos relatados por Oliveira et al. (1982), cujos valores foram entre $6,85 \mathrm{e} 10,13 \mathrm{~cm}$, e Vasconcellos et al. (1993), que obtiveram média de 9,59cm.

TABELA 1 - Efeitos dos sistemas de condução, irrigação e poda sobre a qualidade dos frutos e rendimento do maracujazeiro doce, durante as safras de 1997 e 1998. Selvíria -MS.

\begin{tabular}{|c|c|c|c|c|c|c|}
\hline \multicolumn{2}{|c|}{ Tratamentos } & $\begin{array}{c}\text { Diâmetro } \\
\text { dos frutos }(\mathrm{cm})\end{array}$ & $\begin{array}{l}\text { Comprimentodos } \\
\text { frutos }(\mathrm{cm})\end{array}$ & $\begin{array}{c}\text { Massa } \\
\text { dos frutos }(\mathrm{g})\end{array}$ & $\begin{array}{c}\text { Número } \\
\text { de frutos por planta }\end{array}$ & $\begin{array}{c}\text { Rendimento } \\
(\mathrm{t} / \mathrm{ha})\end{array}$ \\
\hline \multirow{3}{*}{$\begin{array}{l}\text { Sistema de condução } \\
\text { (SC) }\end{array}$} & "T" normal & $7,10 \mathrm{a}$ & $10,74 \mathrm{a}$ & $197,93 \mathrm{a}$ & $50,12 \mathrm{~b}$ & $15,78 \mathrm{~b}$ \\
\hline & E.V. -1 fio de arame ${ }^{1}$ & $7,18 \mathrm{a}$ & $10,56 \mathrm{a}$ & $197,13 \mathrm{a}$ & $43,03 \mathrm{~b}$ & $13,80 \mathrm{~b}$ \\
\hline & E.V. -2 fios de arame ${ }^{2}$ & $7,04 \mathrm{a}$ & $10,93 \mathrm{a}$ & $189,11 \mathrm{a}$ & $68,83 \mathrm{a}$ & $21,95 \mathrm{a}$ \\
\hline $\mathrm{CV} \%$ & & 7,70 & 5,22 & 15,21 & 15,57 & 18,45 \\
\hline DMS & & 0,7966 & 0,8170 & 43,0871 & 13,8063 & 4,6122 \\
\hline Teste F para SC & & $0,18 \mathrm{~ns}$ & $1,32 \mathrm{~ns}$ & $0,32 \mathrm{~ns}$ & $23,67 * *$ & $21,55 * *$ \\
\hline & Com Irrigação & $7,15 \mathrm{a}$ & $10,71 \mathrm{a}$ & $198,63 \mathrm{a}$ & $55,88 \mathrm{a}$ & $18,03 \mathrm{a}$ \\
\hline Irrigação (I) & Sem Irrigação & $7,06 \mathrm{a}$ & $10,78 \mathrm{a}$ & $190,82 \mathrm{a}$ & $52,10 \mathrm{a}$ & $16,33 \mathrm{a}$ \\
\hline $\mathrm{CV} \%$ & & 4,87 & 6,38 & 15,45 & 44,19 & 43,18 \\
\hline DMS & & 0,2823 & 0,5589 & 24,5292 & 19,4588 & 6,0499 \\
\hline Teste F para I & & $0,59 \mathrm{~ns}$ & $0,11 \mathrm{~ns}$ & $0,61 \mathrm{~ns}$ & $0,22 \mathrm{~ns}$ & $0,47 \mathrm{~ns}$ \\
\hline & Com Poda & $7,26 \mathrm{a}$ & $10,77 \mathrm{a}$ & $211,72 \mathrm{a}$ & $40,83 \mathrm{~b}$ & $14,89 \mathrm{~b}$ \\
\hline Poda (P) & Sem poda & $6,95 \mathrm{a}$ & $10,72 \mathrm{a}$ & $177,74 \mathrm{~b}$ & $67,16 \mathrm{a}$ & $19,50 \mathrm{a}$ \\
\hline $\mathrm{CV} \%$ & & 6,90 & 5,61 & 18,48 & 24,75 & 30,71 \\
\hline DMS & & 0,3564 & 0,4377 & 26,1260 & 9,7022 & 3,8304 \\
\hline Teste $\mathrm{F}$ para $\mathrm{P}$ & & $3,50 \mathrm{~ns}$ & $0,07 \mathrm{~ns}$ & $8,02 *$ & $35,00 * *$ & $6,75 * *$ \\
\hline Teste F para SC x I & & $0,17 \mathrm{~ns}$ & $0,71 \mathrm{~ns}$ & $1,42 \mathrm{~ns}$ & $12,21 \mathrm{~ns}$ & $3,28 \mathrm{~ns}$ \\
\hline Teste $\mathrm{F}$ para $\mathrm{SC} \times \mathrm{P}$ & & $0,71 \mathrm{~ns}$ & $0,35 \mathrm{~ns}$ & $0,31 \mathrm{~ns}$ & $14,22 * *$ & $11,26^{* *}$ \\
\hline Teste F para I x P & & $1,25 \mathrm{~ns}$ & $0,09 \mathrm{~ns}$ & $0,06 \mathrm{~ns}$ & $0,01 \mathrm{~ns}$ & $0,00 \mathrm{~ns}$ \\
\hline Teste F para SC x I x P & & $2,62 \mathrm{~ns}$ & $3,61 \mathrm{~ns}$ & $4,29 *$ & $0,03 \mathrm{~ns}$ & $1,13 \mathrm{~ns}$ \\
\hline
\end{tabular}


TABELA 2 - Médias da massa por fruto em função de poda e irrigação, em três sistemas de condução, para o maracujazeiro doce, nas safras de 1997 e 1998. Selvíria-MS.

\begin{tabular}{|c|c|c|c|c|c|c|c|c|}
\hline \multirow[b]{3}{*}{ Sistemas de Condução } & \multicolumn{8}{|c|}{ Massa dos Frutos (g) } \\
\hline & \multicolumn{2}{|c|}{ Com Irrigação } & \multicolumn{2}{|c|}{ Sem irrigação } & \multicolumn{2}{|c|}{ Com Poda } & \multicolumn{2}{|c|}{ Sem Poda } \\
\hline & $\begin{array}{l}\text { Com } \\
\text { poda }\end{array}$ & $\begin{array}{l}\text { Sem } \\
\text { poda }\end{array}$ & $\begin{array}{l}\text { Com } \\
\text { poda }\end{array}$ & $\begin{array}{l}\text { Sem } \\
\text { poda }\end{array}$ & $\begin{array}{c}\text { Com } \\
\text { irrigação }\end{array}$ & $\begin{array}{c}\text { Sem } \\
\text { irrigação }\end{array}$ & $\begin{array}{c}\text { Com } \\
\text { irrigação }\end{array}$ & $\begin{array}{c}\text { Sem } \\
\text { irrigação }\end{array}$ \\
\hline "T" normal & $227,32 \mathrm{abA}$ & $166,00 \mathrm{aA}$ & $210,47 \mathrm{aA}$ & $187,93 \mathrm{aA}$ & $227,32 \mathrm{aA}$ & $210,47 \mathrm{aA}$ & $166,00 \mathrm{aA}$ & $187,93 \mathrm{aA}$ \\
\hline E.V. -1 fio de arame ${ }^{1}$ & $244,67 \mathrm{aA}$ & $181,27 \mathrm{aA}$ & $188,92 \mathrm{aA}$ & $173,68 \mathrm{aA}$ & $244,67 \mathrm{aA}$ & $188,92 \mathrm{aA}$ & $181,27 \mathrm{aA}$ & $173,68 \mathrm{aA}$ \\
\hline E.V. -2 fios de arame ${ }^{2}$ & $170,26 \mathrm{bA}$ & $202,27 \mathrm{aA}$ & $228,67 \mathrm{aA}$ & $155,28 \mathrm{aB}$ & $170,26 \mathrm{aA}$ & $228,67 \mathrm{aB}$ & $202,27 \mathrm{aA}$ & $155,28 \mathrm{aA}$ \\
\hline
\end{tabular}

1.Espaldeira vertical com um fio de arame.

2. Espaldeira vertical com dois fios de arame

Médias seguidas de mesma letra, minúscula na vertical e maiúscula na horizontal, não diferem entre si, pelo Teste de Tukey, a $5 \%$ de probabilidade.

\section{Massa dos frutos}

Verifica-se pela Tabela 1 que houve interação entre o sistema de condução x irrigação x poda. O desdobramento dessa interação (Tabela 2) mostra que houve diferença no sistema de condução apenas na condição de irrigação e poda. A maior massa por fruto foi obtida com a espaldeira vertical com um fio de arame, embora não tenha diferido estatisticamente do "T" normal. Verifica-se também que, para plantas não-irrigadas, a poda propiciou maior massa por fruto, de modo significativo, apenas na condição de espaldeira vertical com dois fios de arame. Nesta condição, observa-se que poda e irrigação apresentaram menor massa. Provavelmente, isto se deve à competição interna em função da maior produção de frutos por planta, nesta condição.

Quanto à massa média dos frutos, os valores obtidos (entre 177,74 e 211,72g) são semelhantes aos encontrados por Rossini (1977), em Jaboticabal (160 a 240g), ao avaliar plantas de Passiflora alata Ait., e inferior aos obtidos em Botucatu-SP, por Vasconcellos et al. (1993), que foi de $256,13 \mathrm{~g}$.

\section{Número de frutos por planta}

A produção média do maracujazeiro doce nos dois anos de produção foi de aproximadamente 54 frutos por planta (Tabela 1).

As interações entre o sistema de condução e a poda (Tabela 3) mostram que houve diferença estatística significativa entre os sistemas de condução para plantas podadas, sendo que o maior número de fruto (71,49 frutos/planta) foi obtido na espaldeira vertical com 2 fios de arame, que diferiu dos obtidos nos demais sistemas de condução. Martins et al. (2003), trabalhando com diversos genótipos de maracujazeiro doce, verificaram que o número de frutos produzidos por planta variou entre 7 e 346, para cultivo no espaçamento 6,0 × 3,5 m.. Entre as plantas nãopodadas, não houve diferença estatística significativa entre os sistemas de condução.

Os resultados da poda, dentro de cada sistema de condução, permitem verificar que, para a condução das plantas em "T" normal, houve diferença estatística significativa entre plantas podadas e nãopodadas, sendo que a poda reduziu em aproximadamente $68 \%$ o número de frutos por planta. Da mesma forma, verifica-se redução com relação à espaldeira vertical com 1 fio de arame, evidenciando ser a poda prejudicial a esses dois sistemas de condução. Por outro lado, verifica-se que, para o sistema de condução em espaldeira vertical com 2 fios de arame, não houve diferença estatística significativa entre plantas podadas e nãopodadas, com relação ao número de frutos por planta. Buell (1955) verificou em maracujazeiro roxo aumento do número de frutos quando conduzido com poda severa (deixando ramos com 2 nós).

O resultado obtido na espaldeira vertical com dois fios de arames, provavelmente, está relacionado com o maior número de ramos, pois as plantas foram conduzidas com cordões nos dois fios de arames, o que poderá ter possibilitado o desenvolvimento de um maior número de brotos nessas plantas, permitindo maior produção.

\section{Rendimento por área}

A produção média do maracujazeiro doce, nos dois anos de produção, foi de aproximadamente 17,2 t/ha (Tabela 1).

As interações entre o sistema de condução e a poda (Tabela 3) mostram que houve diferença estatística significativa entre os sistemas de condução para plantas podadas, sendo que o maior rendimento por área $(25,27 \mathrm{t} / \mathrm{ha})$ foi obtido na espaldeira vertical com 2 fios de arame, que diferiu dos obtidos nos demais sistemas de condução. Martins et al. (2003), trabalhando com diversos genótipos de maracujazeiro doce, verificaram que a produção variou entre 1,43 e $69,87 \mathrm{~kg}$ de frutos por planta, para cultivo no espaçamento $6,0 \times 3,5 \mathrm{~m}$. Entre as plantas nãopodadas não houve diferença estatística significativa entre os sistemas de condução.

Os resultados da poda dentro de cada sistema de condução permitem verificar que, para a condução das plantas em "T" normal, houve diferença estatística significativa entre plantas podadas e nãopodadas, sendo que a poda reduziu em aproximadamente $59 \%$ o a produção por área. Da mesma forma, verifica-se redução com relação à espaldeira vertical com 1 fio de arame, evidenciando ser a poda prejudicial a esses dois sistemas de condução. Por outro lado, verifica-se que, para o sistema de condução em espaldeira vertical com 2 fios de arame, não houve diferença estatística significativa entre plantas podadas e nãopodadas, com relação à produção por área.

TABELA3 - Médias do número de frutos por planta e rendimento em função de poda e sistemas de condução, para o maracujazeiro doce, das safras de 1997 e 1998. Selvíria-MS.

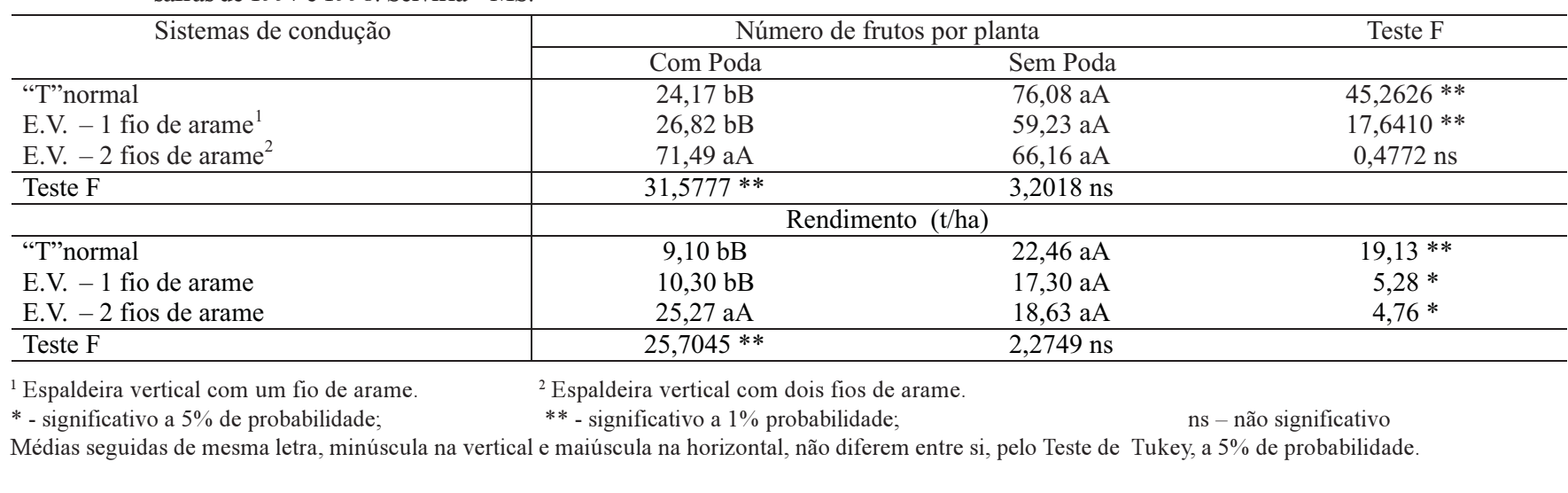

Rev. Bras. Frutic., Jaboticabal - SP, v. 26, n. 3, p. 450-453, Dezembro 2004 
Bower e Dedolph (1959) constataram que poda severa reduz a produção do maracujazeiro amarelo, propiciando inclusive morte de ramos. Por outro lado, verificou-se, no presente trabalho, florescimento das plantas o ano todo, com pico em maio/junho. Desta forma, outras pesquisas devem ser realizadas visando a tratamentos de poda menos drásticos, bem como outras épocas de realização de poda.

Por outro lado, verifica-se que, para o sistema de condução em espaldeira vertical com 2 fios de arame, não houve diferença estatística significativa entre podadas e não-podadas, com relação ao rendimento das plantas. Tal efeito pode ser devido à planta ter maior número de ramos, uma vez que foi conduzida nos dois fios de arame.

\section{CONCLUSÕES}

Com base nos resultados obtidos, nas condições da região onde foi conduzido o experimento, pode-se concluir: a) o sistema de condução e a poda não afetaram o tamanho dos frutos; b) o sistema de condução não afetou a massa dos frutos, porém as plantas podadas produziram frutos com maior massa; c) a poda diminuiu o número de frutos por planta e o rendimento por área, nos sistemas de condução em T normal e espaldeira vertical com um fio de arame; d) a poda não alterou o número de frutos por planta e o rendimento por área, no sistema de condução em espaldeira vertical com dois fios de arame.

\section{REFERÊNCIAS}

ALBUQUERQUE, J. A. S.; ALBUQUERQUE, T. C. S. Prática de cultivo para maracujá na região do submédio do São Francisco. Petrolina: EMBRAPA-CPATSA, 1988. 12p.

BOWERS, F.A.; DEDOLPH, R.R. A preliminary report on pruning of passion fruit. Hawaii Farm Science, Honolulu, v.7, n.4, p.6-8, 1959.

BUELL, E. P. Training and pruning the passion vine. Tropical Agriculturist, Sri Lanka, v.1, n.111, p.18-27, 1955.

CENTURION, J. F. Balanço hídrico na região de Ilha Solteira. Científica, Jaboticabal, v.10, n.1, p. 57-61, 1982.

CEREDA, E. Influência da poda na frutificação do maracujá (Passiflora edulis f flavicarpa Deg.). Ciência e Cultura, São Paulo, v.28, supl. ,p.800, 1976.

CEREDA, E.; URASHIMA, A. S. Estudo comparativo do florescimento em ramos podados e não podados no maracujazeiro $P$. edulis $\operatorname{Sims} f$. flavicarpa DEG. In: CONGRESSO BRASILEIRO DE FRUTICULTURA, 10., 1989, Fortaleza. Anais... Fortaleza: Sociedade Brasileira de Fruticultura, 1989. p.371-85.

CEREDA, E.; FERREIRA, G Sistema de condução e manejo da cultura do maracujazeiro. In: SIMPÓSIO DA CULTURA DO MARACUJAZEIRO, 5., 1998, Jaboticabal. Anais... Jaboticabal: Funep , 1998 .p. 93-101.
DEMATTÊ, J. L. I. Levantamento detalhado dos solos do Campus Experimental de Ilha Solteira. Piracicaba: ESALQ-USP, 1980. 114p. EMBRAPA - Sistema Brasileiro de Classificação de Solos. Brasília: Serviço de Produção de Informação, 1999. 412p.

LUCAS, A.A.T. Resposta do maracujazeiro amarelo (Passiflora edulis f. flavicarpa Deg.) a lâminas de irrigação e doses de adubação potássica. 2002. 88f. Dissertação (Mestrado em Agronomia) - Escola de Agricultura Luiz de Queiroz, Universidade de São Paulo, Piracicaba, 2002.

MANICA, I. Fruticultura tropical: 1. Maracujá, São Paulo: Agronômico Ceres, 1981. 160p.

MARTINS, M.R. Seleção de genótipos de maracujazeiro-doce (Passiflora alata Dryand.) em Jaboticabal SP. Jaboticabal, 2002. 83f. Tese (Doutorado em Genética e Melhoramento de Plantas), Faculdade de Ciências Agrárias e Veterinárias, Universidade Estadual Paulista, Jaboticabal, 2002.

MARTINS, M.R.; OLIVEIRA, J.C.; DI MAURO, A.O.; SILVA, P.C. Avaliação de populações de maracujazeiro doce (Passiflora alata Curtis) obtidas de polinização aberta. Revista Brasileira de Fruticultura, Jaboticabal, v.25, n. 1, p.111-114, 2003.

OLIVEIRA, J.C.; RUGGIERO.C.; NAKAMURA, K. Variações observadas em frutos de Passiflora alata Ait. Proceedings of the American Society Horticultural Science, Campinas, v.25, n.1, p.343-345, 1982.

OLIVEIRA, A. M. A. Reprodução e citogenética de sp. de Passiflora. 1996. 148f. Tese (Doutorado em Genética) - Instituto de Biociências Letras e Ciências Exatas, Universidade Estadual Paulista, São José do Rio Preto, 1996.

ROSSINI, A. C. Características botânicas e agronômicas de plantas de Passiflora alata Ait. (maracujá-guassu) cultivados em Jaboticabal. 1977. 46f. Monografia (Trabalho de Graduação em Agronomia) Faculdade de Ciências Agrárias e Veterinárias, Universidade Estadual Paulista, Jaboticabal, 1977.

RUGGIERO, C. Cultura do maracujazeiro. Ribeirão Preto: Legis Summa, 1987.250p.

TEIXEIRA, C. G Maracujá: cultura. In: ITAL. Maracujá: cultura, matériaprima, processamento e aspectos econômicos. Campinas, 1994. p.1142.

VASCONCELLOS, M. A. S.; CEREDA, E.; ANDRADE, J.M.B.; BRANDÃO FILHO, J.U.T. Desenvolvimento de frutos do maracujazeiro doce (Passsiflora alata Dryand.), nas condições de Botucatu-SP. Revista Brasileira de Fruticultura, Cruz das Almas, v.15, n.1, p.153-8, 1993. 